of the upper gastrointestinal tract are more common in iron deficient patients with webs than those without, suggesting that autoimmunity is a factor in Paterson-Kelly syndrome. It is reported that treatment with iron and correction of anaemia may sometimes relieve dysphagia but without necessarily altering the radiological appearance of the web itself. Whether such treatment has any effect on the estimated $5 \%$ risk of malignant change in the pharyngo-oesophageal region is uncertain. ${ }^{4}$

Oesophageal web remains an uncommon cause of dysphagia in childhood but one which may be suggested by careful history taking and clinical examination. Barium swallow can be diagnostic but false negative or misleading results sometimes occur particularly if reluctance to drink the barium results in poor dilatation of the pharynx insufficient for the web to be visualised. ${ }^{2}$ The lack of information regarding postcricoid dysphagia in childhood makes the prognosis for our patient impossible to define. When the diagnosis is not made until adult life there may be a history of dysphagia going back to childhood. One such case, a male diagnosed at the age of 38, developed squamous cell carcinoma of the pharynx 10 years later. ${ }^{6}$ Our patient has so far only been followed up for a few months but as the risk of malignancy is particularly worrying in a young child we plan to keep him under regular review with repeat pharyngoscopy at six monthly intervals, whether symptomatic or not.

\section{References}

${ }^{1}$ Brown-Kelly A. Spasm at the entrance to the oesophagus. $J$ Laryngol Otol 1919;34:285-9.

2 Klifto EJ, Allen SK, Metzman M, Chase PJ, Kupersmit M. Plummer-Vinson syndrome: report of a case and review of the literature. Journal of the American Osteopathic Association 1983;83:56-9.

${ }^{3}$ Wynder EL, Fryer JH. Etiologic considerations of PlummerVinson (Paterson-Kelly) syndrome. Ann Intern Med 1958;49:1106-28.

4 Chisholm M, Ardran GM, Callender ST, Wright R. A follow-up study of patients with post-cricoid webs. $Q J$ Med 1971;40:409 20.

5 Chisholm M, Ardran GM, Callender ST, Wright R. Iron deficiency and autommunity in post-cricoid webs. $Q J$ Med 1971;40:421-33.

${ }^{6}$ Logan J S. A review of the Plummer-Vinson stricture of the cervical oesophagus. Ulster Med J 1978;47(suppl 2):1-14.

Correspondence to Dr J W L Puntis, Institute of Child Health, Francis Road, Edgbaston, Birmingham B16 8ET.

Accepted 26 August 1988

\title{
High compared with standard dose lipase pancreatic supplement
}

\author{
P J ROBINSON, ${ }^{*}$ A OLINSKY,${ }^{*}$ A L SMITH, $\dagger$ AND S B CHITRAVANSHI \\ ${ }^{*}$ Professorial Department of Thoracic Medicine and †Department of Gastroenterology, Royal Children's \\ Hospital, Melbourne, Australia, and $¥$ Medical Services, Organon International, The Netherlands
}

SUMMARY Cotazym-S-Forte, a new pancreatic supplement containing $10000 \mathrm{BP}$ units of lipase activity per capsule, was compared with a standard dose pancreatin supplement (Pancrease) with 5000 BP units lipase activity in a randomised crossover trial. The number of capsules of Cotazym-S-Forte administered was half the usual number of Pancrease capsules and was associated with the same degree of fat absorption as Pancrease.

Relative deficiency of exocrine pancreatic enzymes occurs in about $85 \%$ of patients with cystic fibrosis. ${ }^{1}$ Within any group of patients with cystic fibrosis there is a wide range of requirements for pancreatic enzyme supplements. ${ }^{2}$ The large number of capsules required by some patients may contribute to poor compliance. If the number of capsules could be reduced while maintaining adequate fat absorption this would be of benefit to the patients.

The aim of this present study was to compare a high lipase dose, enteric coated, enzyme supplement (Cotazym-S-Forte (Organon), 10000 BP units lipase activity per capsule) with a standard lipase dose enteric coated, enzyme supplement (Pancrease (Cilag), 5000 BP units lipase activity per capsule). It was reasoned that the same degree of fat absorption could be achieved with half the number of capsules. This study was performed to test this hypothesis.

\section{Patients and methods}

Thirty patients with cystic fibrosis ( 20 boys, 10 girls) ranging in age from 1.3 years to 13.8 years (mean $4 \cdot 7$ years) participated in the study. Each patient had classic features of cystic fibrosis and a sweat chloride concentration $>60 \mathrm{mmol} / \mathrm{l}$ on pilocarpine ion- 
tophoresis. At entry into the study all patients were taking Pancrease.

The study consisted of two 14 day periods, one while taking the usual dose of Pancrease and the other while taking Cotazym-S-Forte. The number of Cotazym-S-Forte capsules was calculated to be half the usual number of Pancrease capsules. When the number of Pancrease capsules was an odd number the lower half was taken. Patients were randomly allocated to commence with either Pancrease or Cotazym-S-Forte. Sixteen patients took Pancrease in the first 14 day period of the study and 14 Cotazym-S-Forte. Each 14 day period terminated with a three day fat balance study performed at home. This consisted of a full dietary recording for four days with a faecal collection during the last three days of this period. No restriction was placed on fat intake during the study period. As a further check that the fat intake was similar in both periods and represented by the dietary record at the end of the period, however, a further two days of dietary recording was performed mid way through each 14 day period separate from the recording period for the fat balance study.

Faecal fat estimation was calculated using the acid titration method of van de Kramer et al. ${ }^{3}$ Fat content of ingested foods was calculated from the dietary records using the Microdiet software package (Department of Mathematics and Statistics, University of Salford, United Kingdom). Where necessary, additional foodstuffs were added to the programme using values from Australian dietary references. ${ }^{45}$ The percentage of fat malabsorbed was calculated by the equation:

$$
\% \text { Fat malabsorbed }=\frac{\text { Three day fat output }(\mathrm{g})}{3 \times \text { Mean daily fat intake }(\mathrm{g})}
$$

Fat malabsorption values on each supplement, average number of capsules taken for the 14 day period, and fat intake during periods when faecal collection was, and was not performed, were compared using the paired $t$ test. The study was approved by the hospital ethics committee and written parental consent was obtained.

\section{Results}

Twenty five patients successfully completed the 28 day study period. One patient taking Cotazym-SForte withdrew from the study after developing diarrhoea. Three patients were excluded because of incomplete and inaccurate dietary recording and a further patient was withdrawn due to incomplete faecal collection. There was no significant difference between the fat input during periods of faecal collection and periods during the two week study period where dietary recording was performed without faecal collection. The degree of fat malabsorption while taking Pancrease and Cotazym-SForte was not significantly different (figure). The mean degree of malabsorption while on Pancrease was $12 \%$ and on Cotazym-S-Forte $13 \%$. The group mean intake for Pancrease was 31 capsules a day (range 10-56), while for Cotazym-S-Forte the figure was 14 capsules a day (range 6-25). This represents an average daily lipase input of 15500 units (range 5000 to 28000 units) while on Pancrease, and 14000 units (range 6000 to 25000 units) while on CotazymS-Forte.

\section{Discussion}

The results of the present study have shown that Cotazym-S-Forte is as effective as Pancrease in reducing the fat malabsorption in patients with cystic fibrosis. Cotazym-S-Forte has the added advantage that the number of capsules needed are half that of Pancrease. It would therefore be of benefit to those patients who require large amounts of pancreatic enzyme supplements to correct their fat malabsorption. Reducing the number of capsules would probably also lead to greater compliance with

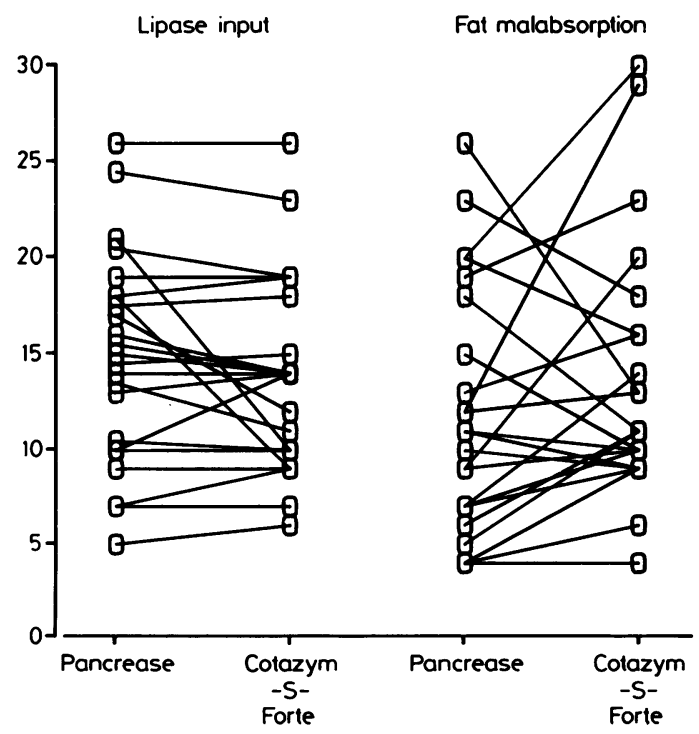

Figure Left: average daily lipase input (1000s of international units) during the two periods of faecal collection. Right: fat malabsorption, as a percentage of ingested fat, while taking Pancrease and while taking Cotazym-S-Forte. 
the medication. Despite instructions to reduce the number of capsules by only half when taking Cotazym-S-Forte, some patients reduced it by more than half without any significant alteration in fat malabsorption. This does not negate the results of this study as the aim of this study was to determine if Cotazym-S-Forte was as effective as Pancrease, not that it necessarily had better activity.

Individual microspheres of Cotazym-S-Forte have a mean (SD) diameter of $1.2 \mathrm{~mm}(0.4 \mathrm{~mm})$, (personal communication, Organon) a size smaller than the average quoted size for Pancrease microspheres, $<3 \mathrm{~mm}$ (product information, Cilag). Meyer et al have shown that while sphere size in the 1-3 $\mathrm{mm}$ range determines the rate of emptying from the stomach (independent of meal composition), microspheres should be in the range of $1.4(0.3) \mathrm{mm}$ to empty at the same rate as emulsified food. (Meyer J, Elashoff J, Porter-Fink V, Dressman J, Amidon G. What should be the size of pancreatin microspheres? Abstract presented at the American Gastroenterological Association Meeting, Chicago, May 1987.) Thus the microsphere size may be the reason why some patients were able to reduce their capsule intake to less than half their usual Pancrease dose without an alteration in the degree of fat malabsorption. Another possible and more likely explanation for the reduction in enzyme intake by more than half is that these patients were taking an excessive number of Pancrease capsules initially.

All patients involved with the study expressed preference for the Cotazym-S-Forte preparation due to the reduced number of capsules required. No side effects were noted. The diarrhoea experienced by one patient while on Cotazym-S-Forte is unlikely to have been a side effect as several members of his family, who do not have cystic fibrosis, had similar symptoms at the same time. The preparation appears to be safe and acceptable.

With the advent of enteric coated pancreatic supplements our ability to provide adequate nutrition in cystic fibrosis has improved due to the greater utilisation of fat as an energy source. While it remains likely that in the foreseeable future enzymes will still be needed, a reduction in the number of capsules required would be of major benefit to these patients.

The results of this study have shown that Cotazym-S-Forte is as effective as Pancrease in correcting fat malabsorption in cystic fibrosis and has the added advantage of needing only about half the number of capsules.

The authors wish to thank Organon for their help with the project. They also wish to thank Mrs B Crawford who performed the faecal fat assays.

\section{References \\ ${ }^{1}$ Wong LT, Turtle S, Davidson AG. Secretin pancreozymin stimultation test and confirmation of the diagnosis of cystic fibrosis. Gut 1982;23:744-55. \\ 2 Graham D. Ins and outs of pancreatic enzymes and adjuvant therapies. J Pediatr Gastroenterol Nutr 1984;3(suppl 1):S120-6. \\ 3 Van de Kramer JH, ten Bokkel Huiniak H, Weyers HA. Rapid method for determination of fat in feces. J Biol Chem 1949;177:347-55. \\ ${ }^{4}$ Greenfield $\mathrm{H}$, ed. The nutrient composition of Australian meats and poultry. Food technology in Australia. 1987;39: 181-240. \\ 5 Thomas S, Corden M. Metric tables of composition of Australian foods. Canberra: Commonwealth Department of Health Food and Nutrition Section, 1977.}

Correspondence to Dr PJ Robinson, Professorial Department of Thoracic Medicine, Royal Children's Hospital, Flemington Road, Parkville, Victoria 3052, Australia.

Accepted 11 August 1988

\title{
Spontaneous regression of congenital epulis of the newborn
}

\author{
H R JENKINS AND C M HILL* \\ Departments of Child Health and *Oral Surgery, University Hospital of Wales
}

SUMMARY An infant with congenital gingival epulis which spontaneously regressed over the first year of life is reported. A policy of conservative management should be adopted in this condition unless there are feeding problems in the newborn period or reasons to doubt the diagnosis.
Congenital epulis of the newborn is a rare, benign tumour of the gingiva first described in $1871 .{ }^{1}$ The aetiology and histological origin of the tumour are unknown and there are still doubts as to the natural history of the condition. The optimal management of congenital epulis is unclear and some authors have recommended simple excision in the neonatal period. $^{2}$ This report concerns an infant who pre- 